\title{
The metabolic syndrome among Danish seafarers: a follow-up study
}

\author{
Jørgen Riis Jepsen ${ }^{1,2}$, Hanna B. Rasmussen ${ }^{1,3}$ \\ ${ }^{1}$ Centre of Maritime Health and Society, Institute of Public Health, University of Southern Denmark, Esbjerg, Denmark \\ ${ }^{2}$ Department of Occupational Medicine, Hospital of Southwestern Jutland, Esbjerg, Denmark \\ ${ }^{3}$ Centre for Quality, Region of Southern Denmark, Middelfart, Denmark
}

\begin{abstract}
Background: The metabolic syndrome (MS) represents a cluster of risk factors related to insulin resistance. Metabolic syndrome is a strong risk factor for chronic metabolic and cardiovascular diseases and is related to nutritional factors, sleep patterns, work-related stress, fatigue, and physical activity - all of which are critical issues at sea. We have previously demonstrated a MS prevalence of $24.2 \%$ in Danish seafarers. This study aimed to follow the trend of MS after 2 years' intervention.

Materials and methods: Out of 524 Danish seafarers (mean age 37.7 years) who underwent medical fit-for-duty examination by seamen's doctors at baseline, 141 seafarers (mean age 41.3 years) were tracked and re-examined after 2 years. At baseline all participants received general advice regarding lifestyle issues. Seafarers with MS were additionally given specific advice regarding treatment. The seafarers provided questionnaire information about their workplace on board, about treatment of hyperlipidaemia, hypertension, and about previously diagnosed type 2-diabetes. In order to define MS, we collected data about waist circumference, blood pressure, triglycerides, HDL-cholesterol, and fasting plasma glucose. Results: Out of 35 (26.5\%) seafarers who fulfilled the criteria for MS at follow-up, 18 had MS at baseline while 9 were incident cases. Two seafarers with MS at baseline ceased to qualify for this condition at follow-up. The prevalence of seafarers with MS at follow-up represents a minimal estimate because a proportion could not be assessed due to missing fasting blood tests. Smoking and alcohol consumption was not reduced. Conclusions: In spite of the intervention, the prevalence of MS increased in this group of seafarers. This study indicates the limitations of individual health promotion and the need for corporate actions.
\end{abstract}

(Int Marit Health 2016; 67, 3: 129-136)

Key words: metabolic syndrome, seafarers, nutrition, smoking, alcohol consumption, Denmark

\section{INTRODUCTION}

The metabolic syndrome (MS) represents a cluster of risk factors related to insulin resistance. The International Diabetes Federation (IDF) defines MS as a constellation of increased waist circumference in combination with dyslipidaemia, hyperglycaemia, and/or increased blood pressure (BP) (Table 1) [1]. The prevalence of MS is rising in a global perspective [2], and MS is currently present in $1 / 5$ of the adult Danish population [3]. Metabolic syndrome is a strong predictor for type 2 diabetes and cardiovascular diseases for which it increases the risk 6 and 5 times, respectively [4]. Metabolic syndrome contributes to $1 / 3$ of cardiovascular diseases and doubles the related mortality [5]. In addition, MS is strongly associated with arterial hypertension, non-alcoholic fatty liver, polycystic ovary syndrome and certain malignancies.

The number of people with MS increases worldwide [4]. There is a social gradient in the prevalence of MS, and the relative susceptibility differs in between various populations. Asians, who currently represent a major proportion of seafarers on Danish flagged ships, seem to be at particular risk of MS $[6,7]$. The distribution within the two sexes differs in various populations. In Denmark, males, who represent 
Table 1. Definition of metabolic syndrome according to the International Diabetes Federation [1]

\begin{tabular}{lll}
\hline Factor & Criteria & Women \\
\cline { 2 - 3 } & Men & $\geq 80 \mathrm{~cm}$ \\
\hline $\begin{array}{l}\text { Increased waist circumference } \\
\begin{array}{l}\text { Plus any } 2 \text { of the following factors: } \\
\text { Raised triglycerides } \\
\text { or specific treatment for this lipid abnormality }\end{array}\end{array}$ & $>94 \mathrm{~cm}$ & $>1.7 \mathrm{mmol} / \mathrm{L}$ \\
$\begin{array}{l}\text { Reduced high density lipoprotein-cholesterol } \\
\text { or specific treatment for this lipid abnormality }\end{array}$ & $<1.03 \mathrm{mmol} / \mathrm{L}$ & $<1.29 \mathrm{mmol} / \mathrm{L}$ \\
$\begin{array}{l}\text { Raised blood pressure } \\
\text { or treatment of previously diagnosed hypertension } \\
\text { Raised fasting blood plasma glucose } \\
\text { or previously diagnosed type 2 diabetes }\end{array}$ & Systolic $\geq 130 \mathrm{~mm} \mathrm{Hg}$ or diastolic $\geq 85 \mathrm{~mm} \mathrm{Hg}$ \\
\end{tabular}

the majority of seafarers, have a higher prevalence than females. Metabolic syndrome has a strong aetiological relation to nutritional factors, sleep patterns, current [8] or previous shift work [9], work-related stress [10], fatigue [11], and physical activity [12] - all of which are critical issues at sea.

The management of MS is primarily based on the treatment of identified hypertension, hyperlipidaemia or diabetes, which may well be asymptomatic. In addition, dietary habits, physical activity and risks imposed by smoking and alcohol consumption should be addressed either by individual counselling or in combination with health promotion directed to risk environments such as a single vessel, a shipping company or a seafaring community. The latter may include interventions addressing psychosocial issues and, e.g. sleep options, on board.

In a previous study, we have estimated that $24.2 \%$ of participating seafarers (25.9\% of males, $10.7 \%$ of females) who consulted a seamen's doctor for health examination fulfilled the criteria for MS; $30.6 \%$ were current smokers. This figure was based on the assumption, that the rate of MS is the same in subjects who had blood samples drawn as the rate in subjects where this was not possible. Their alcohol consumption was comparable to that of Danes ashore, but exceeded recommendations in $18.6 \%$ [13].

The aim of this study was to assess the effect after 2 years of an intervention, which intended to target the risk factors for MS and the seafarers' consumption of tobacco and alcohol.

\section{MATERIALS AND METHODS}

The study complied with the Helsinki Declaration and was approved by the local Ethics Committee (Ref. no. S-20110039). Signed informed consent was obtained from all the participants.

\section{MATERIALS}

Baseline data were collected from the beginning of October 2011 until the end of June 2012 in four authorised seamen's doctors' clinics in Denmark. Out of 655 Danish seafarers attending for medical fitness examination, 527 seafarers accepted the invitation. Due to missing information, data for 524 seafarers were analysed (Fig. 1) [13]. The participating seamen's doctors were selected because they showed their interest in this study. We have regarded the sampling of seafarers to be examined from these four clinics to be representative for Danish seafarers in general [13].

At follow-up after 2 years from October 2013 to July 2014 , seafarers who participated at baseline were invited for re-examination in the same seamen's doctors' clinics; 141 seafarers accepted the invitation (Fig. 1). Characteristics for participants at baseline and at follow-up are illustrated in Table 2.

\section{METHODS}

Intervention: The intervention consisted of three parts.

a) Through flyers and posters, the participating seafarers were informed about MS, the related risk factors and its health effects.

b) Individuals with MS were given advice relating to treatment of e.g. hyperlipidaemia, hypertension and diabetes when needed.

c) Individuals with MS were advised about preventive measures (10\% weight-reduction, physical activity $>1 / 2 \mathrm{~h} /$ /day, reduced intake of saturated fat, increased content of fibres, smoking cessation and controlled intake of alcohol). The seafarers received the intervention at baseline only. They were invited to contact the research team if necessary but no one needed further advice from our side. All seafarers could contact their general practitioner for advice.

Examination: In addition to the normal content of the medical examination of seafarers, e.g., measurement of BP, the waist circumference was measured as the horizontal circumference of the body, midway between the lower rib and the topmost iliac crest. 


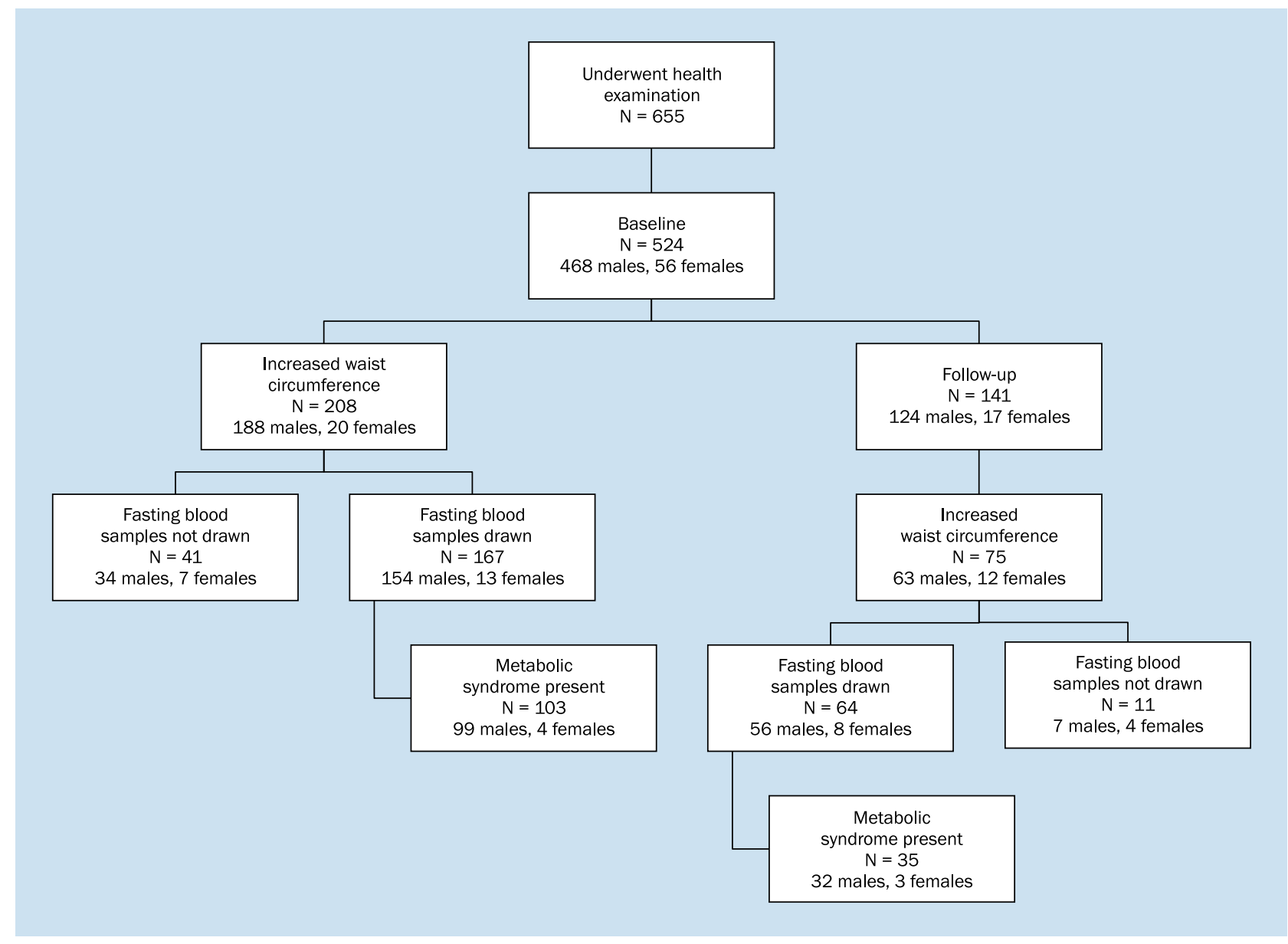

Figure 1. The studied samples at baseline and follow-up

Table 2. Participants in the follow-up study

\begin{tabular}{|c|c|c|c|c|}
\hline & \multicolumn{4}{|c|}{ Study participants $(n=141)$} \\
\hline & \multicolumn{2}{|c|}{ Males $-n=124(88.0 \%)$} & \multicolumn{2}{|c|}{ Females $-n=17(12.0 \%)$} \\
\hline & Mean \pm SD & Range & Mean \pm SD & Range \\
\hline Age [years] & $44.8 \pm 10.9$ & $23-66$ & $29.9 \pm 7.4$ & $18-46$ \\
\hline Body mass index $\left[\mathrm{kg} / \mathrm{m}^{2}\right]$ & $27.6 \pm 4.6$ & $19.2-40$ & $26.2 \pm 5.4$ & $19.6-40$ \\
\hline Waist circumference $[\mathrm{cm}]$ & $96.9 \pm 12.7$ & $65-131$ & $88.4 \pm 14.3$ & $67-112$ \\
\hline
\end{tabular}

Seafarers with a waist circumference exceeding the limits for defining MS (Table 1) [2] proceeded to have fasting blood samples drawn for analysis of triglycerides, high-density lipoprotein (HDL)-cholesterol, and glucose. Non-fasting individuals were asked to come back later or to consult their general practitioner for fasting blood samples.

Sex, date of birth, height, weight, and BP were recorded for participants as well as non-participants. For each individual seafarer, the age and body mass index (BMI) was calculated.

The participants were interviewed about their workplace on board (Table 3), and about anamnestic information in- cluded in the definition of MS (Table 1). They were additionally asked about their smoking and drinking habits ashore and on board, respectively.

The participating and non-participating seafarers at baseline did not differ demographically from all Danish seafarers who consult a seamen's doctor for medical certification [13]. Whether the seafarers who participated in the follow-up study are representative compared with the baseline sample was assessed by comparison of their workplace on board and demographic factors such as the means for age, BMI, and sex. There were minor differences between the distribution of the participating seafarers at follow-up 
Table 3. Workplace on board and demographics

\begin{tabular}{lll}
\hline Workplace on board & Baseline: $\mathbf{N}$ (\% of baseline sample) & Follow-up: $\mathbf{N}$ (\% of follow-up sample) \\
\hline Engine & $89(17.6 \%)$ & $30(22.4 \%)$ \\
Deck & $225(44.6 \%)$ & $74(55.2 \%)$ \\
Catering & $60(11.9 \%)$ & $9(6.7 \%)$ \\
Other & $93(18.4 \%)$ & $17(12.7 \%)$ \\
Engine and Deck & $38(7.5 \%)$ & $4(3.0 \%)$ \\
\hline Demography & Baseline: mean \pm standard deviation & Follow-up: mean \pm standard deviation \\
\hline Age $[$ years] & $37.7 \pm 13.6$ & $41.3 \pm 11.5$ \\
Body mass index $\left[\mathrm{kg} / \mathrm{m}^{2}\right]$ & $26.1 \pm 4.4$ & $27.3 \pm 4.7$ \\
Waist circumference $[\mathrm{cm}]$ & $91.2 \pm 12.0$ & $96.0 \pm 12.9$
\end{tabular}

and at baseline with regard to the workplace on board. The relatively higher number of elderly seafarers is to be expected since the study population was 2 years older at follow-up. The slight increase of waist circumference and $\mathrm{BMI}$ should be viewed in this context. Overall, the follow-up sample is regarded as relatively representative (Table 3 ).

\section{STATISTICAL ANALYSIS}

The data were analysed using the statistics package SPSS Statistics ver. 23 with demographic data presented by descriptive statistics. Categorical variables are presented with numbers (N) and percentage (\%) and continuous variables as mean, standard deviation (SD), and range.

\section{RESULTS}

The mean BMI and waist circumference was high at baseline and increased further at follow-up (Table 3). This trend suggests that further deterioration occurred in spite of the intervention.

Table 4 illustrates the data from the baseline study and the follow-up study that contribute to the definition of MS: a) waist circumference and BP, b) information provided by the participants regarding the conditions that are included in the criteria for MS, and c) laboratory data. Out of the 141 seafarers who participated in the follow-up study, the waist circumference according to the IDF criteria [2] exceeded the limit in 75 (63 males, 12 females) (Fig. 1, Table 4). Fasting blood samples were only available for 64 seafarers (56 males and 8 females) (Fig. 1).

Out of the 141 seafarers followed up, MS was diagnosed in 35 (26.5\%). The majority of 32 were males (27.4\%) while 3 (20.0\%) were females (Fig. 1). This percentage is higher than the rate at baseline even when extrapolated based on the assumption that the prevalence of MS was the same among seafarers with increased waist circumference who had blood tests as those in whom blood samples were not obtained (25.9\% and $10.7 \%$, respectively) [13].
Two seafarers with MS at baseline did not qualify for this condition at follow-up. Nine seafarers without MS at baseline fulfilled the criteria at follow-up. The remaining participants had MS at baseline as well as at follow-up. These figures indicate that the prevalence of MS in the studied sample of seafarers increased in spite of the intervention.

There were slightly more current smokers at follow-up (37.7\%) than at baseline (30.6\%) [13]. Only few seafarers drink while on board the vessel, whereas the majority does drink alcoholic beverages ashore and reported a slight increase in the consumption. At baseline, $18.6 \%$ of the seafarers exceeded the maximal level of alcohol consumption recommended by the Danish authorities (14/7 units per week for men and women, respectively) [13]. At follow-up this figure has risen to $19.6 \%$.

\section{DISCUSSION}

We have previously demonstrated a rate of $24.2 \%$ with MS in Danish seafarers [13]. In a 2-year follow-up of the same sample this figure has increased to $26.5 \%$ in spite of an intervention based on advice on healthy lifestyle to all participants and more specific advice relation to treatment and factors that mitigate MS.

The results of this follow-up study should be interpreted with caution. The limited participation of seafarers in this follow-up study is not satisfactory. Tracing the seafarers who participated in the baseline study may have been disturbing and time-consuming in a busy seamen's office. In addition, a proportion of seafarers may have chosen to see a different seamen's doctor after two years and may therefore be lost to follow-up. Finally, the seafarers have become 2 years older during the follow-up period, in which their waist circumference and BMI have also increased (Table 2). These changes contribute to the increased rate of MS, which, however, also indicates that the advice provided to the seafarers about healthy lifestyle was insufficient. 
Table 4. Characteristics of items contained in the definition of metabolic syndrome at baseline and follow-up

\begin{tabular}{|c|c|c|c|c|c|}
\hline \multirow{2}{*}{$\begin{array}{l}\text { Abnormalities according } \\
\text { to IDF criteria [1] }\end{array}$} & & \multicolumn{2}{|l|}{ Males } & \multicolumn{2}{|l|}{ Females } \\
\hline & & $\begin{array}{l}\text { Number of seafarers ex- } \\
\text { ceeding the IDF criteria } \\
\text { (\% of baseline and } \\
\text { follow-up samples) }\end{array}$ & $\begin{array}{l}\text { Number } \\
\text { of seafarers } \\
\text { examined** }\end{array}$ & $\begin{array}{l}\text { Number of seafarers ex- } \\
\text { ceeding the IDF criteria } \\
\text { (\% of baseline and } \\
\text { follow-up samples) }\end{array}$ & $\begin{array}{l}\text { Number of } \\
\text { seafarers } \\
\text { examined** }\end{array}$ \\
\hline \multirow{2}{*}{$\begin{array}{l}\text { Increased waist } \\
\text { circumference }\end{array}$} & Baseline & $188(40.2 \%)$ & 467 & $20(35.7 \%)$ & 56 \\
\hline & Follow-up & $63(53.4 \%)$ & 118 & $12(70.6 \%)$ & 17 \\
\hline \multirow[t]{2}{*}{ Raised triglycerides* } & Baseline & $62(13.2 \%)$ & 153 & $0(0 \%)$ & 13 \\
\hline & Follow-up & $17(30.9 \%)$ & 55 & $3(37.5 \%)$ & 8 \\
\hline \multirow{2}{*}{$\begin{array}{l}\text { Specific treatment for } \\
\text { hypertriglyceridemia }\end{array}$} & Baseline & $2(0.4 \%)$ & 458 & $0(0 \%)$ & 55 \\
\hline & Follow-up & $1(0.8 \%)$ & 123 & $1(6.7 \%)$ & 15 \\
\hline \multirow[t]{2}{*}{ Reduced HDL-cholesterol* } & Baseline & $34(7.3 \%)$ & 153 & $3(5.4 \%)$ & 13 \\
\hline & Follow-up & $13(23.6 \%)$ & 55 & $5(62.5 \%)$ & 8 \\
\hline \multirow{2}{*}{$\begin{array}{l}\text { Specific treatment for hypo- } \\
\text {-HDL-cholesterolaemia }\end{array}$} & Baseline & $19(4.1 \%)$ & 458 & $1(1.8 \%)$ & 55 \\
\hline & Follow-up & $6(4.9 \%)$ & 123 & $2(11.8 \%)$ & 17 \\
\hline \multirow[t]{2}{*}{ Elevated blood pressure } & Baseline & $306(65.4 \%)$ & 451 & $26(46.4 \%)$ & 54 \\
\hline & Follow-up & $103(85.8 \%)$ & 120 & $10(58.5 \%)$ & 17 \\
\hline \multirow{2}{*}{$\begin{array}{l}\text { Treatment of previously } \\
\text { diagnosed hypertension }\end{array}$} & Baseline & $35(7.5 \%)$ & 461 & $2(3.6 \%)$ & 55 \\
\hline & Follow-up & $12(9.7 \%)$ & 124 & $1(5.9 \%)$ & 17 \\
\hline \multirow{2}{*}{$\begin{array}{l}\text { Raised fasting blood } \\
\text { plasma glucose* }\end{array}$} & Baseline & $84(17.9 \%)$ & 153 & $4(7.1 \%)$ & 12 \\
\hline & Follow-up & $31(9.7 \%)$ & 54 & $4(7.1 \%)$ & 12 \\
\hline \multirow{2}{*}{$\begin{array}{l}\text { Previously diagnosed } \\
\text { type } 2 \text { diabetes }\end{array}$} & Baseline & 9 (1.9\%) & 461 & $0(0 \%)$ & 55 \\
\hline & Follow-up & $4(3.8 \%)$ & 106 & $0(0 \%)$ & 17 \\
\hline
\end{tabular}

*Participants who had fasting blood samples drawn; **Slightly diverging due to missing data; IDF - International Diabetes Federation; HDL - high density lipoprotein

The majority of the seafarers ( 75 out of 141 participating seafarers, 53.2\%) had increased waist circumference and should therefore have blood analysed to determine whether MS was present. This turned out to be a challenge as only 61 of these participants were able to provide a blood sample. Consequently, the demonstrated rate of MS represents a minimum figure. Assuming the same distribution of MS among those who did not have blood tests as in those who did, the extrapolated prevalence of the sample is rather $30 \%$ than $26.5 \%$.

The increased waist circumference during the 3 years, from $91.2 \mathrm{~cm}$ baseline to $96.0 \mathrm{~cm}$ at follow-up (Table 3), is worrying. It is known that age is an important determinant for weight gain as well as with respect to increase in waist circumference, with young people more at risk. An Australian study has shown that young people of 25-34 years of age experienced an average gain in weight of $6.7 \mathrm{~kg}$ and in waist circumference of $6.6 \mathrm{~cm}$ during 12 years. The corresponding figures for older people $>70$ years were loss in weight of $4.5 \mathrm{~kg}$ and gain in waist circumference of $0.8 \mathrm{~cm}$ [14]. The gain in BMI and particularly waist circumference of this relatively young group of seafarers is therefore considerably higher than could be expected.
During the last decades, morbidity data on Danish seafarers have caused concern. Hospitalisations due to chronic conditions related to lifestyle are more frequent among seafarers than in the general population $[15,16]$. In particular, the increased rate of cardiovascular deaths of seafarers on board Danish vessels is worrying [17].

Recent studies have demonstrated that Danish seafarers are more overweight than the general Danish population, which is also severely affected by weight problems. With an increasing rate in the last decade, the majority (66\%) of Danish seafarers were overweight in 2010. Furthermore, maritime students who enter the maritime business are already more overweight than other young people [18]. While the increased waist circumference in MS may represent one aspect of obesity, the two concepts differ. Obesity may occur in metabolically healthy subjects [19], and a person within normal weight limits may still have increased waist circumference and share other characteristics of MS. Approximately half of subjects with MS have a BMI below $30 \mathrm{~kg} / \mathrm{m}^{2}[20]$.

Metabolic syndrome represents a serious, widespread, and preventable public health issue. Studies of occupational groups such as construction workers [21], policemen [22] 
and law enforcement personnel [23] have demonstrated rates of MS from $21 \%$ to $26.7 \%$ and comparisons between MS in occupational groups suggested transport workers to be at particular risk [24]. Within occupational groups, the prevalence is likely to differ considerably. A recent study has shown that $51 \%$ of seafarers in two Danish shipping companies fulfilled the criteria for MS [25].

Health promotion can potentially reduce the prevalence of MS. The prevention of MS may, however, be more efficient than, e.g. an isolated focus on weight reduction, because a moderately increased BMI of a physically fit person does not, in itself, call for intervention. Still, interventions targeting overweight are regarded as essential and worksites to be significant settings for weight management programmes. However, most intervention programmes have failed to demonstrate substantial weight loss. A recent study of the feasibility and effectiveness of lifestyle counselling in an occupational setting, however, has demonstrated modest health benefits for men with increased risk [26]. As MS is mostly associated with low cardiovascular fitness [27], physical training would be a key intervention. Further studies are needed to demonstrate effective worksite interventions and to quantify their sustainability [28].

For being declared fit for work on board a ship, seafarers are required to pass a medical examination every second year. While this examination may potentially represent an active health-based selection leading to active seafarers being healthier than the rest of the population, it is not known whether it actually contributes to such "healthy worker" selection. If so, it is also unknown which health factors are influenced and to what extent [29]. In this context, it should be emphasized that the health data that are currently collected during the medical fit for duty examinations are meant to safeguard the safety of the crew and the vessel rather than to promote the individual seafarers' health.

This study has demonstrated the challenges of an intervention study in seamen's doctors' practice with study subjects participating twice. A cultural change such as this intervention that aimed to target MS seems to require a more lengthy and comprehensive intervention than what could be achieved in this study.

Compared with previously, the seafarers' reported alcohol consumption and smoking is now limited. It is, however, worrying that the situation seems to get worse at follow-up in spite of the intervention. The reported rate of current smokers is higher than the general level of Danes, out of which $17 \%$ of adults are smokers. Easy access to cheap duty free cigarettes in overseas shipping may still represent a challenge. The consumption of alcohol on board is now regulated for Danish seafarers in active duty (similar to regulations relating to land-traffic). According to the seafar- ers' responses, drinking on board is now very limited. Still, however, seafarers' reported general alcohol intake while ashore exceeds that of other Danish adults. If the 14-unit limit recommended by the Danish authorities for men is applied, $19.6 \%$ of the seafarers exceeded the weekly maximal consumption while ashore.

Cigarette smoking seems to be an independent risk factor for MS while the risk does not seem to be exaggerated by alcohol intake [30]. However, the additional caloric intake from alcoholic beverages contributes to the metabolic balance.

\section{PERSPECTIVES}

Is the prevalence of MS in this and the previous study [13] alarming? The crude figure suggests that around a quarter of the Danish seafarers have MS and the extrapolated prevalence approaching 30\% may be regarded as only slightly increased. However, the studied seafarers are relatively young (mean age 41.3 years) and therefore should have lower risk of MS. This is of importance since a strong age gradient has been demonstrated in all studies. The strong inverse social gradient in the prevalence of MS demonstrated in a recent Danish study [3] is also important. This study involved a mixed group of seafarers, most of whom were officers, and consequently representing higher social strata, for which one would expect a smaller prevalence of MS. We have not stratified according to social factors but taken together, the composition of our sample representing mostly younger seafarers of whom the majority belongs to the officer group strongly suggests that the demonstrated prevalence of MS is a cause for concern. This is even more worrying when the potentially serious consequences of MS are taken into account.

More importantly, this study has addressed only Danish seafarers and not the foreign crew that today represents a majority of seafarers on Danish merchant vessels. The prevalence of MS among foreign crews is not known, but we are concerned that MS may be more prevalent in foreign seafarers on Danish ships. More severe consequences of MS, in particular for many Asians, who are more prone to diseases such as type 2 diabetes and more exposed to an imbalanced consumption of fats and oils [31], are likely. Deficient health control and management in their home countries are likely to further aggravate the situation. Taking into account the higher risk of MS in Asian seafarers [6, 7] that today represent the majority of the ratings on board Danish ships, one would expect MS to be considerably more frequent if this study was extended to cover crews of any nationality and consequently with a higher share of ratings with non-Danish citizenship.

Better understanding the development of MS would require a study involving a larger population and ideally it 
should also encompass foreign seafarers and in particular those of Asian origin who currently constitute the majority on Danish merchant ships and are likely to be particularly at risk [32].

\section{CONCLUSIONS}

1. $24.2 \%$ of Danish seafarers with a mean age of 37.7 years were estimated to have MS at baseline. Due to the major age-related and social gradient, this prevalence of MS was estimated to be higher than in the general Danish population.

2. $26.5 \%$ of participants at follow-up were diagnosed as MS. This figure is likely to represent a minimum prevalence since the diagnosis of MS requires analyses of blood, which was not possible in a proportion of seafarers. Two seafarers with MS at baseline did not qualify for this condition at follow-up. Nine seafarers developed MS during the observation period.

3. Metabolic syndrome is a major and apparently increasing problem among Danish seafarers.

4. Smoking ashore and on board remains slightly higher than that of all Danes. Alcohol intake is very limited on board, but $19.6 \%$ of Danish seafarers exceed the currently recommended limits while ashore.

5. Preventive intervention should target nutrition, exercise, fatigue (e.g. stress, watch systems and sleep quality), smoking, and alcohol habits.

6. The applied individual intervention for mitigation of MS was clearly insufficient. Collective interventions should be applied in the shipping industry.

7. Future studies should target seafarers irrespective of nationality, in particular Asian crews who are likely to be at particular risk.

\section{ACKNOWLEDGEMENTS}

The authors wish to thank the participating seafarers and the seamen's doctors who collected the data for this study. This study has received financial support by The Danish Maritime Fund.

\section{REFERENCES}

1. The IDF consensus worldwide definition of the metabolic syndrome. Brussels: International Diabetes Federation; 2007 [cited 2016 12.08.16]. Available from: http://www.idf.org/webdata/docs/ IDF_Meta_def_final.pdf.

2. Borch-Johnsen $\mathrm{K}$. The metabolic syndrome in a global perspective. The public health impact-secondary publication. Dan Med Bull 2007; 54: 157-159.

3. Prescott E, Godtfredsen N, Osler M, Schnohr P, Barefoot J. Social gradient in the metabolic syndrome not explained by psychosocial and behavioural factors: evidence from the Copenhagen City Heart Study. Eur J Cardiovasc Prev Rehabil 2007; 14: 405-412. doi: 10.1097/HJR.0b013e32800ff169.
4. Eckel RH, Grundy SM, Zimmet PZ. The metabolic syndrome. Lancet 2005; 365: 1415-1428. doi: 10.1016/S0140-6736(05)66378-7.

5. Nichols M TN, Luengo-Fernandez R, Leal J, Gray A, Scarborough P, Rayner M. European Cardiovascular Disease Statistics 2012. European Heart Network, European Society of Cardiology, Brussels 2012.

6. Eapen D, Kalra GL, Merchant N, Arora A, Khan BV. Metabolic syndrome and cardiovascular disease in South Asians. Vasc Health Risk Manag 2009; 5: 731-743.

7. Misra A, Khurana L. Obesity-related non-communicable diseases: South Asians vs White Caucasians. Int J Obes (Lond) 2011; 35: 167-187. doi: 10.1038/ijo.2010.135.

8. Shift work and sleep: optimizing health, safety, and performance. J Occup Environ Med 2011; 53 (5 Suppl.): S1-S10; quiz S1-2. doi: 10.1097/JOM.0b013e31821aec20.

9. Puttonen S, Viitasalo K, Harma M. The relationship between current and former shift work and the metabolic syndrome. Scand J Work Environ Health 2012; 38: 343-348. doi: 10.5271/sjweh.3267.

10. Almadi T, Cathers I, Chow CM. Associations among work-related stress, cortisol, inflammation, and metabolic syndrome. Psychophysiology 2013; 50: 821-830. doi: 10.1111/psyp.12069.

11. Kaltsas G, Vgontzas A, Chrousos G. Fatigue, endocrinopathies, and metabolic disorders. PM\&R 2010; 2: 393-398. doi: 10.1016/j. pmrj.2010.04.011.

12. Burton WN, Chen CY, Li X, Schultz AB, Abrahamsson H. The association of self-reported employee physical activity with metabolic syndrome, health care costs, absenteeism, and presenteeism. J Occup Environ Med 2014; 56: 919-926. doi: 10.1097/ JOM.0000000000000257.

13. Moller Pedersen SF, Jepsen JR. The metabolic syndrome among Danish seafarers. Int Marit Health 2013; 64: 183-190.

14. Tanamas SK, Shaw JE, Backholer K, Magliano DJ, Peeters A. Twelve -year weight change, waist circumference change and incident obesity: the Australian diabetes, obesity and lifestyle study. Obesity (Silver Spring) 2014; 22: 1538-1545. doi: 10.1002/oby.20704.

15. Hansen HL, Tuchsen F, Hannerz H. Hospitalisations among seafarers on merchant ships. Occup Environ Med 2005; 62: 145-150. doi: 10.1136/oem.2004.014779.

16. Kaerlev L, Dahl S, Nielsen PS et al. Hospital contacts for chronic diseases among Danish seafarers and fishermen: a population-based cohort study. Scand J Public Health 2007; 35: 481-489. doi: 10.1080/14034940701267385.

17. Borch DF, Hansen HL, Burr H, Jepsen JR. Surveillance of maritime deaths on board Danish merchant ships, 1986-2009. Int Marit Health 2012; 63: 7-16.

18. Hansen HL, Hjarnoe L, Jepsen JR. Obesity continues to be a major health risk for Danish seafarers and fishermen. Int Marit Health 2011; 62: 98-103.

19. Sims EA. Are there persons who are obese, but metabolically healthy? Metabolism 2001; 50: 1499-1504. doi: 10.1053/ meta.2001.27213.

20. Arnlov J, Sundstrom J, Ingelsson E, Lind L. Impact of BMI and the metabolic syndrome on the risk of diabetes in middle-aged men. Diabetes Care 2011; 34: 61-65. doi: 10.2337/dc10-0955.

21. Thabit H, Burns N, Shah S et al. Prevalence and predictors of diabetes and cardiometabolic risk among construction workers in Ireland: the Construction Workers Health Trust screening study. Diab Vasc Dis Res 2013; 10: 337-345. doi: 10.1177/1479164113479808.

22. Hartley TA, Burchfiel CM, Fekedulegn D, Andrew ME, Knox SS, Violanti JM. Associations between police officer stress and the metabolic syndrome. Int J Emerg Ment Health 2011; 13: 243-256. 
23. Zimmerman FH. Cardiovascular disease and risk factors in law enforcement personnel: a comprehensive review. Cardiol Rev 2012; 20: 159-166. doi: 10.1097/CRD.0b013e318248d631.

24. Davila EP, Florez H, Fleming LE et al. Prevalence of the metabolic syndrome among U.S. workers. Diabetes Care 2010; 33: 2390-2395. doi: 10.2337/dc10-0681.

25. Hjarnoe L, Leppin A. A risky occupation? (Un)healthy lifestyle behaviors among Danish seafarers. Health Promot Int 2014; 29: 720-729. doi: 10.1093/heapro/dat024.

26. Viitasalo K, Hemio K, Puttonen S et al. Prevention of diabetes and cardiovascular diseases in occupational health care: Feasibility and effectiveness. Prim Care Diabetes 2014; doi: 10.1016/j. pcd.2014.07.008.

27. Lewis JE, Cutrono SE, Hodgson $\mathrm{N}$ et al. Association between cardiovascular fitness and metabolic syndrome among American workers. J Occup Environ Med 2015; 57: 129-133. doi: 10.1097/ JOM.0000000000000391.
28. Roberts SB, Krebs N. Can weight management programs in worksites reduce the obesity epidemic? Adv Nutr 2012; 3: 730-731. doi: 10.3945/an.112.002634.

29. Oldenburg M, Baur X, Schlaich C. Occupational risks and challenges of seafaring. J Occup Health 2010; 52: 249-256. doi: JST.JSTAGE/ joh/K10004.

30. Takeuchi T, Nakao M, Nomura K, Yano E. Association of metabolic syndrome with smoking and alcohol intake in Japanese men. Nicotine Tob Res 2009; 11: 1093-1098. doi: ntp106 [pii] 10.1093/ ntr/ntp106.

31. Misra A, Singhal N, Khurana L. Obesity, the metabolic syndrome, and type 2 diabetes in developing countries: role of dietary fats and oils. J Am Coll Nutr 2010; 29 (3 Suppl.): 289S-301S.

32. Poulsen TR, Burr H, Hansen HL, Jepsen JR. Health of Danish seafarers and fishermen 1970-2010: What have register-based studies found? Scand J Public Health 2014; 42: 534-545. doi: 1403494814534538 